\title{
Insomnia among non-depressed multiple sclerosis patients: a cross-sectional study
}

\author{
A. A. Alhazzani ${ }^{1,4,5^{*}}$, A. Alshahrani ${ }^{2}$, M. Alqahtani $^{3}$, R. Alamri ${ }^{3}$, R. Alqahtani ${ }^{3}$, M. Alqahtani ${ }^{3}$ and M. Alahmarii ${ }^{3}$
}

\begin{abstract}
Background: Insomnia is a common problem that affects approximately $50 \%$ of patients with multiple sclerosis (MS), who suffer from sleep disturbances. In general, persons with insomnia are at a higher risk of developing depression. This study was conducted to assess insomnia among non-depressed MS patients in Saudi Arabia.

Methods: Based on the Patient Health Questionnaire-9 (PHQ-9), those who scored 4 or less for depression out of 598 MS patients were selected $(n=112)$. A cross-sectional study was conducted to interview 112 non-depressed MS patients in order to assess insomnia among them. A data collection sheet has been designed by the researchers. It comprised socio-demographic variables (e.g., gender, age, area of residence, and marital status) and clinical variables (disease duration, age at disease onset, previous diagnosis of depression, and used antidepressant drugs). Insomnia was assessed by the Insomnia Severity Index (ISI), while severity of illness was assessed using the Patient Determined Disease Steps (PDDS).

Results: A total of 72 patients (64.3\%) were females, and 62 (55.4\%) were married. Their mean age was 32.6 years ( $\mathrm{SD}=8.9$ ), ranging from 15 to 56 years. As for educational level, 64 (57.1\%) had a Bachelor degree. The mean age at disease onset was 26 years $(S D=8.9)$. The mean duration of illness was 1.9 years. Symptoms of insomnia were present among 14 patients (12.5\%). No statistical significance was found between the mean PDSS of insomnia and non-insomnia patients. Significant differences were present between insomnia and non-insomnia patients as regards their education level $(P=0.005)$ and use of antidepressant drugs $(P=0.008)$.
\end{abstract}

Conclusions: Prevalence of insomnia among non-depressed MS patients is low. Insomnia is associated with educational and use of antidepressants. Further research is needed to assess severity of different types of insomnia among depressed and non-depressed MS patients.

Keywords: Insomnia, Multiple sclerosis, Depression, Saudi Arabia

\section{Background}

Multiple sclerosis (MS) is a chronic disease of the central nervous system, with disseminated inflammatory lesions and axonal loss, leading to multifocal signs of neurological deficits (Bamer et al. 2008). Nearly 65\% of MS patients suffer from cognitive problems (Rao et al. 1991), resulting in a reduced quality of life (Mitchell et al. 2005). Several factors are thought to negatively influence cognition in MS patients, such as depression (Arnett et al. 2008),

\footnotetext{
*Correspondence: alhazzani@kku.edu.sa

${ }^{1}$ Neurology Section, Department of Medicine, National Guard Health Affairs,

King Abdulaziz Medical City, Riyadh, Saudi Arabia

${ }^{4}$ College of Medicine, King Khalid University, PO Box 4557, Abha 61412, Saudi

Arabia

Full list of author information is available at the end of the article
}

fatigue (Krupp and Elkins 2000), and sleep disturbances (Sater et al. 2015).

Approximately $50 \%$ of MS patients suffer from sleep disturbances (Bamer et al. 2008). Insomnia, in particular, chronic insomnia, should be treated due to its negative effect on quality of life and functional status (Espie et al. 2016). Obstructive sleep apnea is associated with significant morbidity and mortality and should routinely be sought in MS patients complaining of fatigue and daytime sleepiness (Lunde et al. 2013).

Cross-sectional studies have shown prevalence rates over 40\% for insomnia in MS (Stanton et al. 2006; Tachibana et al. 1994), which probably has a multifactorial etiology. Nocturnal symptoms, including cramps, spasms, and neuropathic pain, as well as nocturnal and bladder dysfunction 
symptoms, are frequent and can contribute to sleep disruption (Merlino et al. 2009). Comorbid psychiatric disorders (such as depression and anxiety) may significantly contribute to insomnia in MS (Pokryszko-Dragan et al. 2013; Lunde et al. 2012).

Up to the best of our knowledge, no study to date examined the relation between depression and insomnia in MS patients in Saudi Arabia. Therefore, this study was conducted to assess insomnia among non-depressed MS patients in Saudi Arabia.

\section{Methods}

The present study followed a cross-sectional design. A medical record review was conducted by the researchers for MS patients registered at tertiary care hospitals in five regions within Saudi Arabia (i.e., southern, east, west, middle, and north). They were diagnosed by a neurologist according to the 2005 revised McDonalds criteria (Polman et al. 2005). MS patients who attained a score of 4 or less for depression based on the Patient Health Questionnaire-9 (PHQ-9) (Kroenke et al., 2001) were included in this study $(n=112)$. All patients were of the relapsing-remitting MS type.

The researchers designed a data collection sheet which was used to interview all 112 selected MS patients. It included a set of socio-demographic variables (gender, age, area of residence, educational level, and marital status) and clinical variables (disease duration, age at disease onset, a previous diagnosis of depression and antidepressant drug use). Severity of MS was measured using the Patient Determined Disease Steps (PDDS), a nine-item patient-administered measure of MS-related disability (Learmonth et al. 2013; Vollmer et al. 1999; Kurtzke 1970; Gulick et al. 2011).

Insomnia was assessed by the Insomnia Severity Index (ISI), a questionnaire widely used to investigate individuals' potential insomnia and the extent to which insomnia affects their quality of life. It contains seven items that assess an individual's experience with insomnia on a 5-point Likert scale, with higher scores indicating more severe insomnia (Morin et al. 2011). Based on the ISI, non-depressed MS patients were divided the into two groups, i.e., non-insomnia patients $(n=98)$ with an ISI score of $0-7$ and insomnia patients $(n=14)$, who had any degree of insomnia with a score of more than 7 , regardless of their type of insomnia (Insomnia Severity Index 2016) (Fig. 1).

The Statistical Package for Social Sciences, (SPSS Inc., Chicago, IL, version 21) was used for the statistical analysis of the data. Descriptive statistics were used to summarize the basic features of the collected data. Group differences were assessed using $t$ test to compare the mean independent sample values. When the assumption of the $t$ test is not valid, we used the nonparametric Mann-Whitney $U$ test. The chi-square test was used to examine the relation between two qualitative variables. In all tests, $P \leq 0.05$ was considered as statistically significant.

\section{Results}

Table 1 shows that among the 112 non-depressed MS patients, $72(64.3 \%)$ were females, $62(55.4 \%)$ were married while 46 (41.1\%) were single. Participant patients' mean age was 32.6 years $(\mathrm{SD}=8.9)$, ranging from 15 to 56 years. As for educational level, 64 (57.1\%) had a Bachelor's degree and $20(17.9 \%)$ had a secondary degree. A total of $34(30.4 \%)$ patients lived in the southern region (Aseer), $42(37.5 \%)$ in the middle region, $24(21.4 \%)$ in the eastern region, and $12(10.7 \%)$ in the western region. Regarding the clinical characteristics of non-depressed MS patients, the mean age at disease onset was 26 years $(\mathrm{SD}=8.2)$ and the mean duration of illness was $3.5(\mathrm{SD}=1.9)$ years. The mean number of admissions was $0.8(\mathrm{SD}=1.3)$, while the mean number of attacks during the last 2 years was 1.6 $(\mathrm{SD}=1.9)$. The most commonly received medications were interferon beta-1b (32.1\%) and teriflunomide (17.9\%). Subcutaneous injection was the main routes for

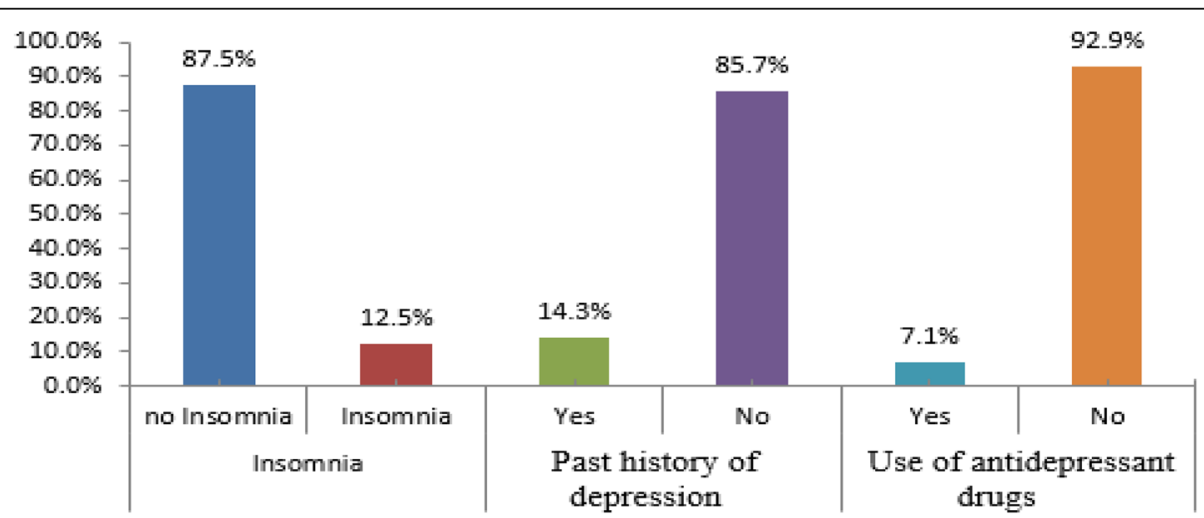

Fig. 1 Distribution of non-depressed patients based on the Insomnia Severity Index. The figure shows that 12.5\% had insomnia symptoms, 85.7\% had past history of depression, and 92.9 and $7.1 \%$ used antidepressant drugs 
Table 1 Demographic and clinical characteristics of study non-depressed MS patients $(n=112)$

\begin{tabular}{|c|c|}
\hline Characteristics & $N(\%)$ \\
\hline \multicolumn{2}{|l|}{ Gender } \\
\hline Male & $40(35.7)$ \\
\hline Female & $72(64.3)$ \\
\hline \multicolumn{2}{|l|}{ Marital status } \\
\hline Single & $46(41.1)$ \\
\hline Married & $62(55.4)$ \\
\hline Divorced & $4(3.6)$ \\
\hline \multicolumn{2}{|l|}{ Education level } \\
\hline Primary & $6(5.4)$ \\
\hline Intermediate & $10(8.9)$ \\
\hline Secondary & $20(17.9)$ \\
\hline Bachelor & $64(57.1)$ \\
\hline Postgraduate & $12(10.7)$ \\
\hline \multicolumn{2}{|l|}{ Region } \\
\hline Southern & $34(30.4)$ \\
\hline Middle & $42(37.5)$ \\
\hline East & $24(21.4)$ \\
\hline West & $12(10.7)$ \\
\hline \multicolumn{2}{|l|}{ Age (years), mean $\pm S D 32.6 \pm 8.9$} \\
\hline \multicolumn{2}{|c|}{ Age at disease onset (years), mean \pm SD $26 \pm 8.2$} \\
\hline \multicolumn{2}{|c|}{ Disease duration (years), mean \pm SD $3.5 \pm 1.9$} \\
\hline \multicolumn{2}{|c|}{ Number of admissions, mean \pm SD $0.8 \pm 1.3$} \\
\hline \multicolumn{2}{|c|}{ Number of attacks during last 2 years, mean \pm SD $1.6 \pm 1.9$} \\
\hline \multicolumn{2}{|l|}{ Medications used } \\
\hline Interferon beta-1b (betaferon) & $36(32.1)$ \\
\hline Teriflunomide (aubagio) & $20(17.9)$ \\
\hline Dimethylfumarate (tecfidera) & $24(21.4)$ \\
\hline Rituximab (rituxan) & $18(16.1)$ \\
\hline Alemtuzumab (lemetrada) & $14(12.5)$ \\
\hline \multicolumn{2}{|l|}{ Routes of drug administration } \\
\hline Oral & $20(17.9)$ \\
\hline Subcutaneous & $52(46.4)$ \\
\hline Intramuscular & $32(28.6)$ \\
\hline Intravenous & $8(7.1)$ \\
\hline
\end{tabular}

drug administration (46.4\%), followed by intramuscular injection $(28.6 \%)$, orally $(17.9 \%)$ and intravenously $(7.1 \%)$.

Table 2 shows that MS patients' characteristics (age, age at disease onset, disease duration, number of hospital admissions, number of attacks during the last year and PDDS) did not differ significantly according to having insomnia.

Table 3 shows that prevalence of insomnia among MS patients differed significantly according to their educational level $(P=0.005)$, being absent among less educated
Table 2 Comparison of MS patients' characteristics according to presence of insomnia

\begin{tabular}{|c|c|c|c|c|c|}
\hline \multirow[b]{2}{*}{ Characteristics } & \multicolumn{2}{|c|}{$\begin{array}{l}\text { Non-insomnia } \\
(n=98)\end{array}$} & \multicolumn{2}{|c|}{$\begin{array}{l}\text { Insomnia } \\
(n=14)\end{array}$} & \multirow[t]{2}{*}{$P$ value } \\
\hline & $\overline{\text { Mean }}$ & SD & $\overline{\text { Mean }}$ & SD & \\
\hline$\overline{\text { Age (years) }}$ & 32.59 & 9.09 & 32.86 & 7.47 & 0.917 \\
\hline Age at disease onset (years) & 25.76 & 8.22 & 27.86 & 7.81 & 0.370 \\
\hline Disease duration (years) & 8.46 & 14.95 & 5.29 & 3.22 & 0.711 \\
\hline $\begin{array}{l}\text { Number of hospital } \\
\text { admissions }\end{array}$ & 0.78 & 1.38 & 0.86 & 1.03 & 0.299 \\
\hline $\begin{array}{l}\text { Number of attacks } \\
\text { during last } 2 \text { years }\end{array}$ & 1.59 & 1.87 & 2.00 & 2.29 & 0.606 \\
\hline $\begin{array}{l}\text { Patient Determined } \\
\text { Disease Steps (PDDS) }\end{array}$ & 1.67 & 1.33 & 1.57 & 1.09 & 0.965 \\
\hline
\end{tabular}

(primary or intermediate levels) patients $(0 \%)$ and highest among postgraduate educated patients (50\%). Moreover, prevalence of insomnia was significantly higher among those who received antidepressant medications $(P=0.008)$. However, prevalence of insomnia did not differ significantly according to patients' sex, marital status, region, route of medication administration, and past history of depression.

\section{Discussion}

To our best knowledge, this is the first study to assess prevalence of insomnia symptoms among non-depressed MS patients in Saudi Arabia. Results demonstrated that only $12.5 \%$ of non-depressed MS patients suffered from insomnia. This finding is lower than that reported by Stanton et al. (2006), who found that $42 \%$ of MS patients had difficulty in initiating sleep, 53\% reported extended awakenings, and 58\% reported waking and being unable to return to sleep at least twice per week. However, they did not exclude MS patients with depression.

Moreover, Lunde et al. (2012) reported that depressed MS patients have more sleep disturbance. This indicates that depression may be associated with insomnia. Nevertheless, more studies are needed to assess insomnia among depressed versus non-depressed MS patients.

In another study, Baron et al. (2011) demonstrated that patients with comorbid MS and depression have levels of insomnia symptoms above and beyond those reported of the overall MS population, with over three quarters of the sample reporting clinically significant insomnia symptoms. The study of Gupta and Lahan (2011) found that subjects with depressive disorder showed symptoms of primary insomnia.

Our study revealed no statistically significant differences in prevalence of insomnia among MS patients according to their gender. However, some studies suggested a higher prevalence of sleep disturbances in female patients (Bamer et al. 2008; Lunde et al. 2012). 
Table 3 Associations regarding socio-demographic variables between insomnia and no insomnia groups in non-depressed MS patients

\begin{tabular}{|c|c|c|c|c|c|c|}
\hline \multirow{2}{*}{ Characteristics } & & \multicolumn{2}{|c|}{ No insomnia } & \multicolumn{2}{|c|}{ Insomnia } & \multirow[t]{2}{*}{$P$} \\
\hline & & No. & $\%$ & No. & $\%$ & \\
\hline \multirow[t]{2}{*}{$\overline{\text { Sex }}$} & Male & 32 & 80.0 & 8 & 20.0 & 0.133 \\
\hline & Female & 66 & 91.7 & 6 & 8.3 & \\
\hline \multirow[t]{3}{*}{ Marital status } & Single & 42 & 91.3 & 4 & 8.7 & 0.136 \\
\hline & Married & 54 & 87.1 & 8 & 12.9 & \\
\hline & Divorced & 2 & 50.0 & 2 & 50.0 & \\
\hline \multirow[t]{5}{*}{ Educational level } & Primary & 6 & 100.0 & 0 & 0.0 & 0.005 \\
\hline & Intermediate & 10 & 100.0 & 0 & 0.0 & \\
\hline & Secondary & 18 & 90.0 & 2 & 10.0 & \\
\hline & Bachelor & 58 & 90.6 & 6 & 9.4 & \\
\hline & Postgraduate & 6 & 50.0 & 6 & 50.0 & \\
\hline \multirow[t]{4}{*}{ Region } & Southern & 30 & 88.2 & 4 & 11.8 & 0.525 \\
\hline & Middle & 36 & 85.7 & 6 & 14.3 & \\
\hline & East & 20 & 83.3 & 4 & 16.7 & \\
\hline & West & 12 & 100.0 & 0 & 0.0 & \\
\hline \multirow[t]{4}{*}{ Route of drug administration } & Oral & 18 & 90.0 & 2 & 10.0 & 0.861 \\
\hline & SC & 48 & 92.3 & 4 & 7.7 & \\
\hline & $\mathrm{IM}$ & 28 & 87.5 & 4 & 12.5 & \\
\hline & IV & 2 & 100.0 & 0 & 0.0 & \\
\hline \multirow{2}{*}{$\begin{array}{l}\text { Past history } \\
\text { of depression }\end{array}$} & Yes & 12 & 75.0 & 4 & 25.0 & 0.114 \\
\hline & No & 86 & 89.6 & 10 & 10.4 & \\
\hline \multirow[t]{2}{*}{ Antidepressant medications } & Yes & 4 & 50.0 & 4 & 50.0 & $0.008^{*}$ \\
\hline & No & 94 & 90.4 & 10 & 9.6 & \\
\hline
\end{tabular}

*P value was calculated according to Fisher's exact test, since more than $25 \%$ of expected values were less than 5

In this study, the educational level is related to insomnia among non-depressed MS patients, where insomnia increases with a higher level of education.

For our insomnia patients, most were classified as subthreshold insomnia (ISI score 8-14). Previous studies reported that the most frequent disturbances reported by MS patients included terminal insomnia, followed by middle and initial insomnias. Waking too early has been described as a common problem among MS patients (Stanton et al. 2006; Caminero and Bartolomé 2011).

Depression may also contribute to insomnia in MS as we figure out those patients who were using antidepressant medications have less insomnia than who did not. Identification and aggressive management of these problems are important, as there is mounting evidence of a bidirectional relationship between sleep and depression, such that insomnia treatment may improve symptoms of these other disorders (Taylor et al. 2007).

\section{Study limitations}

This study had some methodological limitations. The inclusion of MS patients initially depended upon patients' records and self-rating scales and did not include physician-dependent scales. The sample size was limited due to the strict inclusion criteria followed in this study. In future, a study with a larger sample may be planned to unravel this issue. The assessment of some associated symptoms, (e.g., fatigue or nocturia), which may constitute major causes for sleep disturbance among MS patients, were not assessed in this study. Body mass index of patients was not assessed in relation to insomnia. MS patients with insomnia were not further categorized into different types of insomnia. Moreover, the researchers considered that depressed MS patients, whether on antidepressant medications or not, should be studied, though antidepressant medications may affect their sleep. However, since the followed study design was cross-sectional, we could not examine the isolated effect of antidepressant therapy on either of the insomnia groups.

\section{Conclusions}

This study demonstrated a low prevalence of insomnia among non-depressed MS patients. Insomnia was associated with higher educational level but no significant 
association with degree of disability, duration of disease, or MS treatment used. Additional research, particularly with larger sample sizes, is needed to assess further the level of insomnia for depressed and non-depressed MS patients in Saudi Arabia.

\section{Abbreviations}

ISI: Insomnia Severity Index; MS: Multiple sclerosis; PDDS: Patient Determined Disease Steps; PHQ-9: Patient Health Questionnaire-9

\section{Authors' contributions}

AAA contributed to the methodology, data collection, analysis, writing, and reviewing of the manuscript. AA, MA, and RA contributed to the methodology, data collection, analysis, and writing of the manuscript. RAQ contributed to the methodology, data collection, and analysis. MAQ contributed to the methodology, data collection, analysis, writing, and reviewing of the manuscript. MAH contributed to the data collection, analysis, and reviewing of the manuscript. All authors read and approved the final manuscript.

\section{Ethics approval and consent to participate}

The ethical approval for conducting this study was obtained from Head of Research Ethics Committee (HA-06-B-001) in King Khalid University (REC) \# 2016-08-23). The informed consent of participants was obtained prior to their participation in this study.

\section{Competing interests}

The authors declare that they have no competing interests.

\section{Publisher's Note}

Springer Nature remains neutral with regard to jurisdictional claims in published maps and institutional affiliations.

\section{Author details}

${ }^{1}$ Neurology Section, Department of Medicine, National Guard Health Affairs, King Abdulaziz Medical City, Riyadh, Saudi Arabia. ${ }^{2}$ Neurology, Prince Sultan Military Medical City, Riyadh, Saudi Arabia. ${ }^{3}$ Neurology, College of Medicine, King Khalid University, Abha, Saudi Arabia. ${ }^{4}$ College of Medicine, King Khalid University, PO Box 4557, Abha 61412, Saudi Arabia. ${ }^{5}$ Neurology Section, Department of Medicine, King Khalid University, P.O. Box 641, Abha, Saudi Arabia.

Received: 22 September 2017 Accepted: 17 October 2017

Published online: 15 June 2018

\section{References}

Arnett PA, Barwick FH, Beeney JE. Depression in multiple sclerosis: review and theoretical proposal. J Int Neuropsychol Soc. 2008;14:691-724.

Bamer AM, Johnson KL, Amtmann D, Kraft GH. Prevalence of sleep problems in individuals with multiple sclerosis. Mult Scler. 2008;14:1127-30.

Baron KG, Corden M, Jin L, Mohr DC. Improvement in insomnia with psychotherapy for depression in patients with multiple sclerosis. J Behav Med. 2011;34(2):92.

Caminero A, Bartolomé M. Sleep disturbances in multiple sclerosis. J Neurol Sci. 2011;309(1):86-91.

Espie CA, Luik Al, Cape J, et al. Digital cognitive behavioural therapy for insomnia versus sleep hygiene education: the impact of improved sleep on functional health, quality of life and psychological well-being. Study protocol for a randomised controlled trial. Trials. 2016;17:257.

Gulick EE, Namey M, Halper J. Monitoring my multiple sclerosis: a patientadministered health-assessment scale. Int J MS Care. 2011;13(3):137-45.

Gupta R, Lahan V. Insomnia associated with depressive disorder: primary, secondary, or mixed? Indian J Psychol Med. 2011;33(2):123.

Insomnia Severity Index. Website: https://www.ons.org/sites/default/files/ InsomniaSeverityIndex_ISI.pdf. Last Accessed 29 June 2016.

Kroenke K, Spitzer RL, Williams JB. The PHQ-9: validity of a brief depression severity measure. J Gen Intern Med. 2001;16(9):606-13.

Krupp LB, Elkins LE. Fatigue and declines in cognitive functioning in multiple sclerosis. Neurology. 2000;55:934-9.
Kurtzke JF. Neurologic impairment in multiple sclerosis and the disability status scale. Acta Neurol Scand. 1970;46:493-512.

Learmonth YC, Mot RW, Sandroff BM, Pula JH, Cadavid D. Validation of patient determined disease steps (PDDS) scale scores in persons with multiple sclerosis. BMC Neurol. 2013;13:37.

Lunde HMB, Aae TF, Indrevåg W, et al. Poor sleep in patients with multiple sclerosis. PLoS One. 2012;7(11):e49996.

Lunde HMB, Bjorvatn B, Myhr K-M, Bø L. Clinical assessment and management of sleep disorders in multiple sclerosis: a literature review. Acta Neurol Scand. 2013;127(Suppl. 196):24-30.

Merlino G, Fratticci L, Lenchig C, et al. Prevalence of "poor sleep" among patients with multiple sclerosis: an independent predictor of mental and physical status. Sleep Med. 2009;10:26-34.

Mitchell AJ, Benito-Leon J, Gonzalez JM, Rivera-Navarro J. Quality of life and its assessment in multiple sclerosis: integrating physical and psychological components of wellbeing. Lancet Neurol. 2005;4:556-66.

Morin $\mathrm{CM}$, Belleville $\mathrm{G}$, Bélanger $\mathrm{L}$, Ivers $\mathrm{H}$. The insomnia severity index: psychometric indicators to detect insomnia cases and evaluate treatment response. Sleep. 2011;34(5):601-8.

Pokryszko-Dragan A, Bilińska M, et al. Sleep disturbances in patients with multiple sclerosis. Neurol Sci. 2013;34(8):1291-6.

Polman CH, Reingold SC, Edan G, Filippi M, Hartung HP, Kappos L, et al. Diagnostic criteria for multiple sclerosis: 2005 revisions to the "McDonald Criteria". Ann Neurol. 2005;58:840-6.

Rao SM, Leo GJ, Bernardin L, Unverzagt F. Cognitive dysfunction in multiple sclerosis. I. Frequency, patterns, and prediction. Neurology. 1991;41:685-91.

Sater RA, Gudesblatt M, Kresa-Reahl K, Brandes DW, Sater PA. The relationship between objective parameters of sleep and measures of fatigue, depression, and cognition in multiple sclerosis. Multiple Scler J Exp Transl Clin. 2015;1:1-8.

Stanton BR, Barnes F, Silber E. Sleep and fatigue in multiple sclerosis. Mult Scler. 2006;12(4):481-6.

Tachibana N, Howard RS, Hirsch NP, et al. Sleep problems in multiple sclerosis. Eur Neurol. 1994;34(6):320-3.

Taylor DJ, Mallory LJ, Lichstein KL, Durrence HH, Riedel BW, Bush AJ. Comorbidity of chronic insomnia with medical problems. Sleep. 2007;30:213-8.

Vollmer TI, Ni W, Stanton S, Hadjimichael O. The NARCOMS patient registry: a resource for investigators. Int J MS Care. 1999;1:12-5.

\section{Submit your manuscript to a SpringerOpen ${ }^{\mathcal{O}}$ journal and benefit from:}

- Convenient online submission

- Rigorous peer review

- Open access: articles freely available online

- High visibility within the field

- Retaining the copyright to your article

Submit your next manuscript at $>$ springeropen.com 